\title{
SERUM FRUCTOSAMINE TARGETING THE TREATMENT OF GESTATIONAL DIABETES MELLITUS
}

\author{
Huy Truong Le ${ }^{1}$, Chi Van Le ${ }^{2}$ \\ ${ }^{1}$ Endocrinology Dept, Cho Ray Hospital \\ ${ }^{2}$ Internal Medicine Department, Hue University of Medicine and Pharmacy,
}

DOI: $10.47122 / v j d e .2020 .40 .1$

Hue University

\begin{abstract}
Background: Currently,the blood glucose control in women with gestational diabetes (GDM) in Vietnam has been still based on the criteria applied for non-pregnant diabetic patients, while these GDM patients require more specific criteria in order to get a better care of the women and the good delivery outcome. Objective: To determine serum fructosamine target as a supporting test for the treatment and follow-up of GDM. Methodology: A prospective study was done in 451women with GDM at Cho Ray Hospital from August 2016 to March 2019.At least 2 of 3 tests (Go, G2 and $\mathrm{HbA} 1 \mathrm{c}$ ) and serum fructosamine were determined every 2-3 week-up until delivery. Result: The target fructosamine reference value at Cho Ray Hospital was $188.5 \pm 42.3 \mu \mathrm{mol} / \mathrm{L}$. Conclusion: The specific target of serum fructosamine in GDM treatment at Cho Ray hospital should be $\leq 188.5 \pm 42.3 \mu \mathrm{mol} / \mathrm{L}$.

Key words: GDM, fructosamine

Main correspondence: Huy Truong Le

Submission date: $2^{\text {th }}$ May 2020

Revised date: $12^{\text {th }}$ May 2020

Acceptance date: $23^{\text {th }}$ June 2020

Email: truonglehuybvcr@yahoo.com.vn

\section{Question}

Gestational diabetes is a condition of carbohydrate intolerance during pregnancy, which is a specific disease in the diabetes classification of the World Health Organization and the American Diabetes Association (ADA). [6]. There was $18 \%$ of GDM directly affected fetal outcome. Common perinatal complications in children include respiratory failure, jaundice, lower blood glucose, trauma, infection, highweight...[2]. However, studies showed that if the pregnancy is detected and positive follow-up of the treatment, the complications due to diabetes can be significantly reduced. A study of Parkland Hospital in Dallas, Texas, USA showed that only $13.9 \%$ of children with respiratory failure in the diabetic mothers had treatment compared with $27.9 \%$ in the untreated group [5]. Therefore, GDM requires more complete and continuous attention and treatment monitoring.

In most endocrine and gynecological clinics, screening, monitoring and evaluation of diabetic treatment are mainly based on examination and evaluation of basic blood glucose test results such as: fasting blood glucose (G0), two-hour postprandial blood glucose (G2), HbA1c (hemoglobin A1c) and total urine analysis. However, in reality, these tests are not always fully performed.
\end{abstract}

Table 1. Practical considerations in monitoring of diabetes andGDM treatment [1], [3]

\begin{tabular}{|l|l|c|c|}
\hline \multicolumn{2}{|l|}{} & Diabetes & GDM \\
\hline Re-examination time & Once a month & Every 2 to 3 weeks \\
\hline \multicolumn{2}{|l|}{ Average glucose test $(\mathrm{AG})$} & 90 days & $14-20$ days \\
\hline \multirow{3}{*}{ Goals of treatment } & $\mathrm{G}_{\mathrm{o}}(\mathrm{mg} / \mathrm{dL})$ & $70-130$ & $95-105$ \\
\cline { 2 - 4 } & $\mathrm{G}_{2}(\mathrm{mg} / \mathrm{dL})$ & $180-200$ & $120-130$ \\
\cline { 2 - 4 } & $\mathrm{A}_{1} \mathrm{c}(\%)$ & 7 & $6-6,5$ \\
\hline
\end{tabular}


The effect of using serum fructosamine in monitoring and supporting the treatment of GDM has been shown to have benefits that help doctors propose the appropriate monitoring and treatment for pregnant women in Cho Ray hospital [4], however, the reference fructosamine value has not been established specifically for GDM patients. It was why we conducted this study to determine specific target Fructosamine value for monitoring and treatment of gestational diabetes.

\section{Subjects and Research Methods}

The study data was extracted from a prospective cohort study. We followed and treated 451 diabetic patients at the Department of Endocrinology of Cho Ray hospital from August 8, 2016 to March 2019.

The study selected all pregnant women was diagnosed with gestational diabetes according to ICD-10 (O24, O24.4, O24.9). They were performed a set of 4 tests including fructosamine, G0 (fasting blood glucose) , G2 (two-hour postprandial blood glucose) and HbAlc at Cho Ray hospital.Tests (G0, G2, HbA1c) must had at least one or two of the three achieve target. Besides, 28 patients received a personal blood glucose meter to monitor G0 and G2 normally regularly at home.

Fructosamine concentration were determined based on serum samples of pregnant women by enzyme reaction test, performin every 2-3 weeks (14-20 days) and using the standard test tool kit of SIEMENS ADVIA ${ }^{\circledR}$ ChemistryFructosamine Reagent (FRUC) with normal reference range from 200 to $285 \mu \mathrm{mol} / \mathrm{L}$. Data were collected at each examination, inputed by MS Excel 2010 and analyzed by Rstudio 3.5.1. The study was approved by the Hospital Ethics Committee that they allowed to perform test in the Endocrinology Clinic of Cho Ray Hospital. The study did notarise to any intervention on the research methods.

\section{Results and Discussion}

\section{Characteristics of research sample}

We followed 451 pregnant women with gestational diabetes with a total of 932 tests in the hospital that 28 women followed blood glucose with a total of 749 regularly tests at home.

Table 2. Maternal and gestational age distribution of study subjects

\begin{tabular}{lclcc}
\hline $\begin{array}{c}\text { Characteristics } \\
(\mathbf{N = 4 5 1 )}\end{array}$ & $\begin{array}{c}\bar{x} \pm \mathbf{S D} \\
(\mathbf{m i n}-\mathbf{m a x})\end{array}$ & \multicolumn{1}{c}{ Group } & $\mathbf{n}$ & \% \\
\hline Maternal & $33,5 \pm 5,1$ & $\leq 20$ years & 6 & 0,6 \\
age(year) & $(19-49)$ & $21-30$ years & 237 & 25,4 \\
& & $31-40$ years & 600 & 64,5 \\
& & $\geq 41$ years & 89 & 9,5 \\
Gestational & $29,1 \pm 6,6$ & the first trimester & 22 & 2,4 \\
age(week) & $(5-42)$ & the second trimester & 340 & 36,5 \\
& & the third trimester & 570 & 61,1 \\
\hline
\end{tabular}

Most pregnant women in the study were aged $>30$ and have the third trimester. The first trimester pregnant women in the study had a history of diabetes in the previous pregnancy.

Table 3. Distribution of tests

\begin{tabular}{lcc}
\hline \multicolumn{1}{c}{ Test } & $\bar{x} \pm$ SD & Min - Max \\
\hline Fructosamine $(\mathrm{N}=932, \mu \mathrm{mol} / \mathrm{L})$ & $214,6 \pm 56,7$ & $46-350$ \\
$\mathrm{G} 0(\mathrm{~N}=919, \mathrm{mg} / \mathrm{dL})$ & $92,5 \pm 21,3$ & $52-224$ \\
$\mathrm{G} 2(\mathrm{~N}=847, \mathrm{mg} / \mathrm{dL})$ & $130,5 \pm 39,3$ & $63-288$ \\
$\mathrm{HbA}_{1} \mathrm{c}(\mathrm{N}=902, \%)$ & $6,0 \pm 0,8$ & $4,2-9,7$ \\
\hline
\end{tabular}




\begin{tabular}{lcc}
\hline Protein $(\mathrm{N}=864, \mathrm{~g} / \mathrm{dL})$ & $6,2 \pm 0,5$ & $4,8-8,6$ \\
$\mathrm{G} 0$ at home $(\mathrm{N}=637, \mathrm{mg} / \mathrm{dL})$ & $112,2 \pm 31,9$ & $43-267$ \\
$\mathrm{G} 2$ at home $(\mathrm{N}=507, \mathrm{mg} / \mathrm{dL})$ & $145,5 \pm 44,4$ & $55-324$ \\
\hline
\end{tabular}

On average, fasting blood glucose and two-hour postprandial blood glucose in the hospital was lower and fluctuated in a narrower range than the results at home.

\section{Correlation between fructosamine and tests}
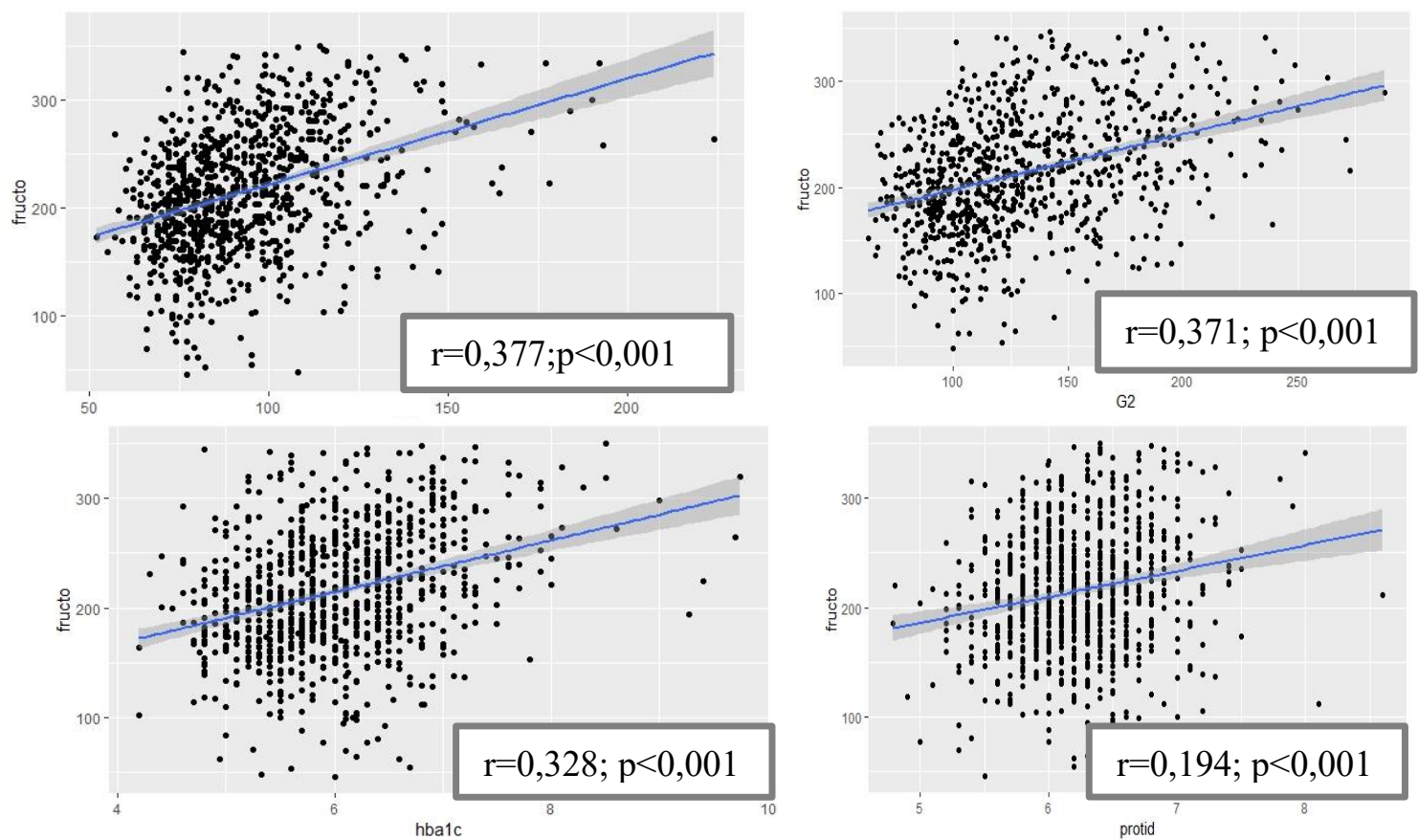

Figure 1. The Spearman correlation between fructosamine and G0, G2, HbA1c and protein in hospital
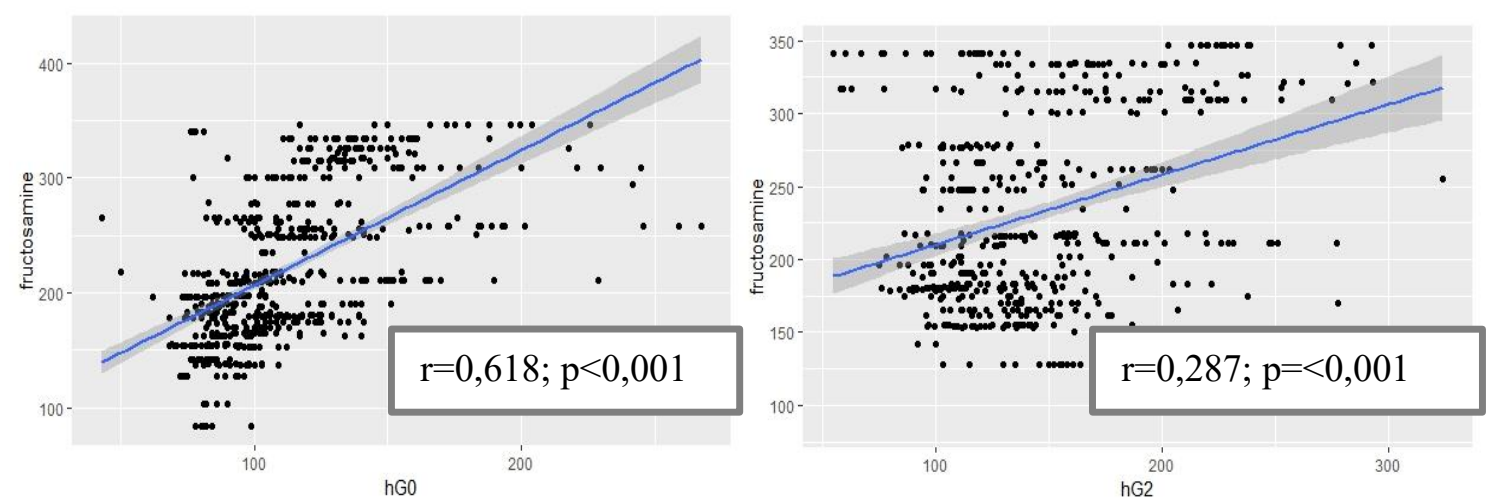

Figure 2. The Spearman correlation between fructosamine and G0, G2 at home 


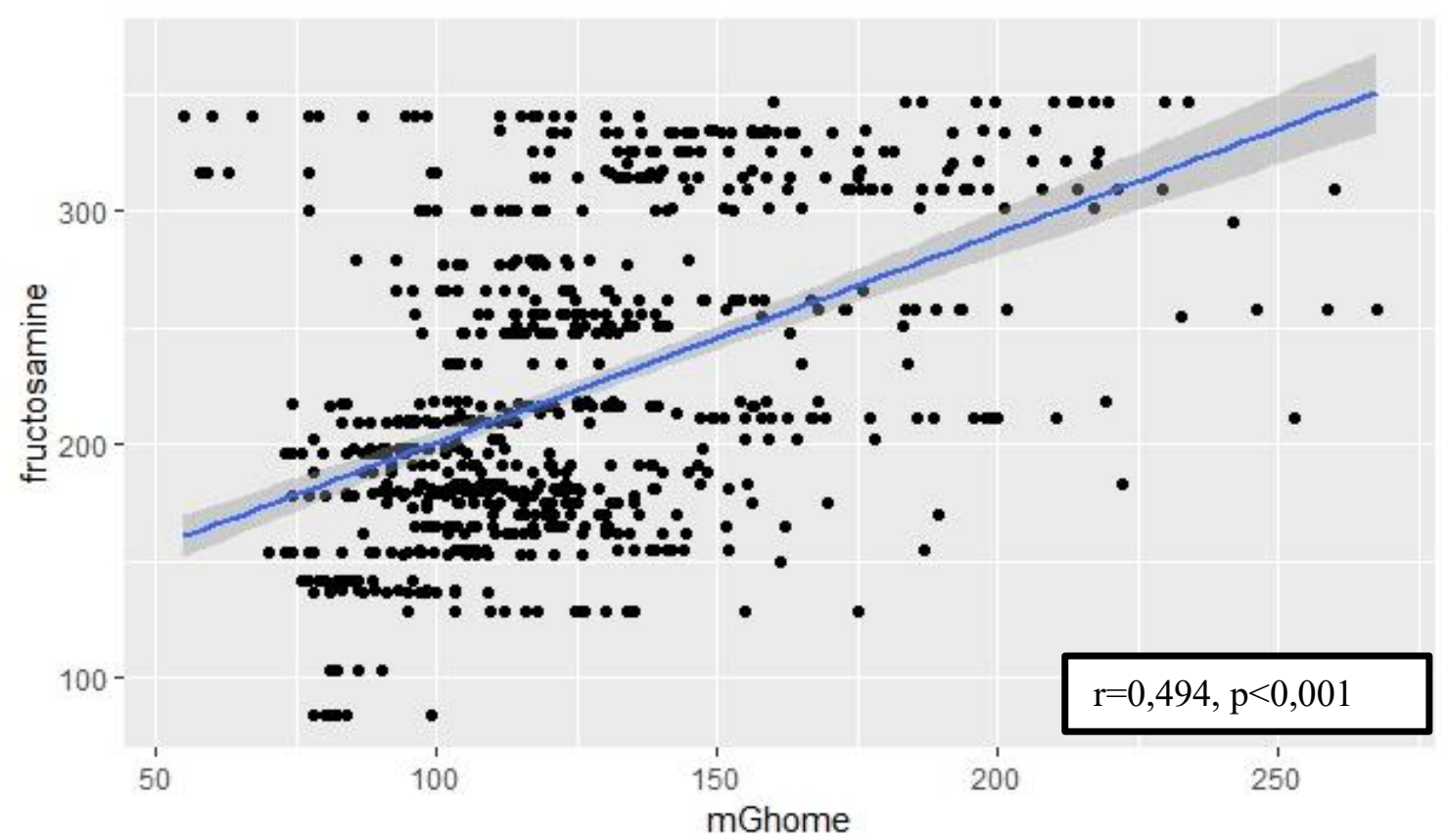

Figure 3. The Spearman correlation between fructosamine and average of $\mathrm{G} 0$ and $\mathrm{G} 2$ at home

Serum fructosamine values were correlated with all other blood glucose and protein values. However, there was a difference in the correlation between the indexes. Fructosamine had a strong correlation with G0 values at home, a moderate correlation with G0, G2, HbA1c values atthe hospital and a G0-G2 at home and it had a weak correlation with a protein values at the hospital and G2 at home.

\begin{tabular}{|c|c|c|c|}
\hline \multirow{2}{*}{ Test } & \multicolumn{2}{|c|}{ Blood glucose measurement at home } & \multirow{2}{*}{$\mathbf{p}^{*}$} \\
\hline & Yes $(\mathrm{N}=62)$ & No $(\mathbf{N}=870)$ & \\
\hline $\mathrm{G} 0(\mathrm{~N}=919, \mathrm{mg} / \mathrm{dL})$ & $94,2 \pm 27,1$ & $92,4 \pm 20,8$ & 0,898 \\
\hline $\mathrm{G} 2(\mathrm{~N}=847, \mathrm{mg} / \mathrm{dL})$ & $125,6 \pm 32,5$ & $130,9 \pm 39,7$ & 0,464 \\
\hline $\mathrm{HbA1c}(\mathrm{N}=902, \%)$ & $6,1 \pm 0,9$ & $6,0 \pm 0,8$ & 0,999 \\
\hline Fructosamine $(\mathrm{N}=932, \mu \mathrm{mol} / \mathrm{L})$ & $223,1 \pm 67,0$ & $214,0 \pm 55,9$ & 0,561 \\
\hline
\end{tabular}

Mann-Whitney test

There was no statistical difference between blood glucose indices between pregnant women with and without home blood glucose meters.. Therefore, using the G0, G2 and HbA1c test has reached the goal at the hospital as a basis for determining the target fructosamine range, regardless of whether the pregnant women have the machine or not was reasonable. 


\section{Target fructosamine value}

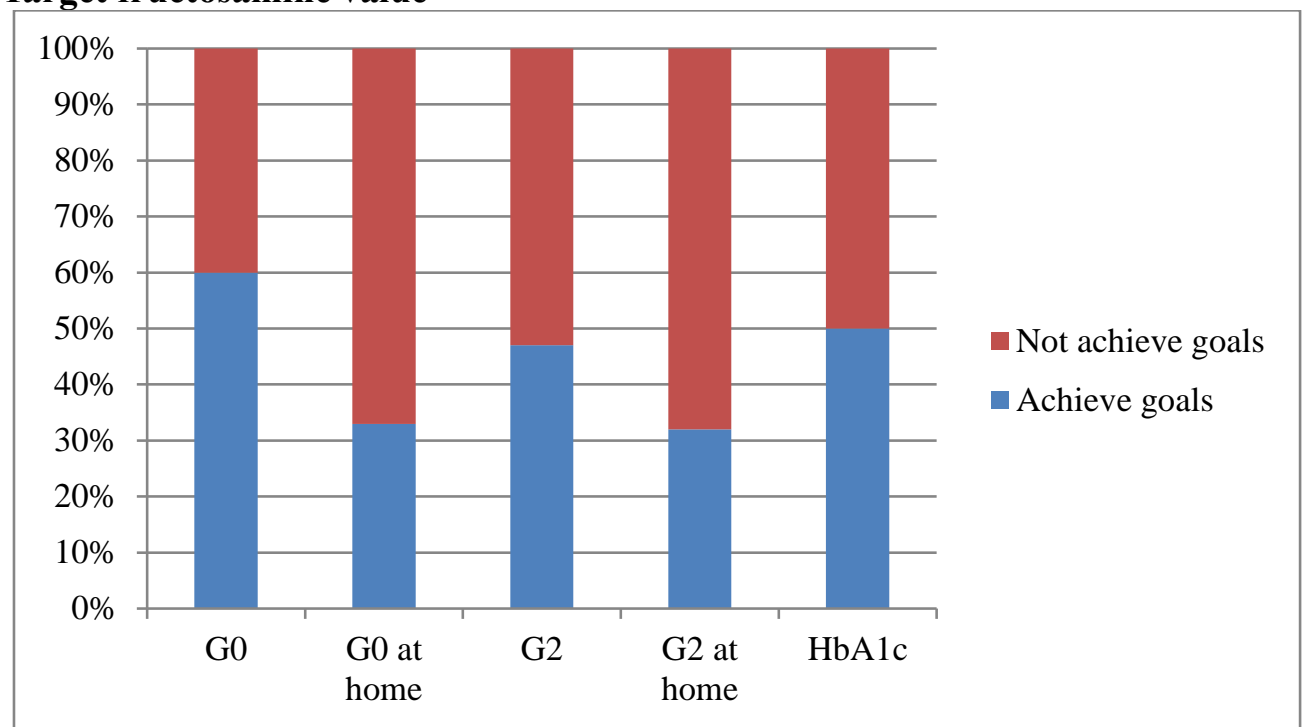

Figure 4. The proportion of target achievement tests

\begin{tabular}{llll}
\hline \multicolumn{1}{c}{ Test } & \multicolumn{1}{c}{ Groups } & $\begin{array}{c}\text { Fructosamine } \\
(\bar{x} \pm \mathbf{S D})\end{array}$ & p* \\
\hline \multirow{2}{*}{$\mathrm{G} 0(\mathrm{~N}=919, \mathrm{mg} / \mathrm{dL})$} & $<95$ & $\mathbf{1 9 9 , 6} \pm \mathbf{5 0 , 5}$ & $<0,001$ \\
& $95-105$ & $227,1 \pm 55,7$ & \\
& $>105$ & $246,8 \pm 58,3$ & \\
$\mathrm{G} 2(\mathrm{~N}=847, \mathrm{mg} / \mathrm{dL})$ & $<120$ & $\mathbf{1 9 4 , 5} \pm \mathbf{4 9 , 5}$ & $<0,001$ \\
& $120-130$ & $212,8 \pm 60,2$ & \\
$\mathrm{HbA}_{1} \mathrm{c}(\mathrm{N}=902, \%)$ & $>130$ & $236,5 \pm 55,2$ & $<0,001$ \\
& $<6$ & $\mathbf{2 0 0 , 9} \pm \mathbf{4 9 , 9}$ & \\
$\mathrm{G} 0$ at home & $6-6,5$ & $217,4 \pm 58,6$ & \\
$(\mathrm{~N}=637, \mathrm{mg} / \mathrm{dL})$ & $>6,5$ & $243,4 \pm 58,5$ & \\
& $<95$ & $\mathbf{1 7 7 , 1} \pm \mathbf{4 5 , 9}$ & \\
$\mathrm{G} 2$ at home & $95-105$ & $197,9 \pm 43,8$ & \\
$(\mathrm{~N}=507, \mathrm{mg} / \mathrm{dL})$ & $>105$ & $260,6 \pm 58,9$ & \\
& $<120$ & $\mathbf{2 1 6 , 7} \pm \mathbf{5 8 , 5}$ & 0,001 \\
& $120-130$ & $222,0 \pm 56,9$ & \\
\hline
\end{tabular}

* Kruskal-Wallis test

Table 4. Fructosamine values by target G0, G2, HbA1c separately

\begin{tabular}{lcc}
\hline Target achievement tests* & $\begin{array}{c}\text { Fructosamine } \\
(\bar{x} \pm \mathbf{S D})\end{array}$ & $\mathbf{p}^{* *}$ \\
\hline $\mathrm{G} 0$ & $\mathbf{1 9 9 , 6} \pm \mathbf{5 0 , 5}$ & $<0,001$ \\
$\mathrm{G} 2$ & $\mathbf{1 9 4 , 5} \pm \mathbf{4 9 , 5}$ & $<0,001$ \\
$\mathrm{HbA} \mathrm{A}_{1}$ & $\mathbf{2 0 0 , 9} \pm \mathbf{4 9 , 9}$ & $<0,001$ \\
$\mathrm{G} 0$ at home & $\mathbf{1 7 7 , 1} \pm \mathbf{4 5 , 9}$ & $<0,001$ \\
$\mathrm{G} 2$ at home & $\mathbf{2 1 6 , 7} \pm \mathbf{5 8 , 5}$ & 0,001 \\
\hline
\end{tabular}


Fructosamine values were statistical differencebetween the target groups of each test. The average fructosamine values in the G0 and G2 target groups at home had moreoscillation than the average fructosamine in the G0, G2 and HbA1c tests that achieved the hospital goal. This result confirmed the reliability of relying on G0, G2 and HbA1c in the hospital to determine the target fructosamine range.

Table 5. Fructosamine values by test groups G0, G2 and HbA1c achieving target at the same time

\begin{tabular}{lccc}
\hline \multicolumn{1}{c}{ Test } & \multicolumn{2}{c}{ Fructosamine } \\
& Achievement * & p & p* \\
& $\mathbf{1 9 1 , 4} \pm \mathbf{4 6 , 4}$ & Not achievement & \\
\hline $\mathrm{G} 0-\mathrm{G} 2(\mathrm{~N}=883)$ & $\mathbf{1 9 4 , 4} \pm \mathbf{4 5 , 4}$ & $228,3 \pm 58,2$ & $<0,001$ \\
$\mathrm{G} 0-\mathrm{HbA}_{1} \mathrm{c}(\mathrm{N}=903)$ & $\mathbf{1 8 8 , 7} \pm \mathbf{4 4 , 1}$ & $228,5 \pm 59,2$ & $<0,001$ \\
$\mathrm{G} 2-\mathrm{HbA}_{1} \mathrm{c}(\mathrm{N}=877)$ & $\mathbf{1 8 8 , 5} \pm \mathbf{4 2 , 3}$ & $226,3 \pm 58,7$ & $<0,001$ \\
$\mathrm{G} 0-\mathrm{G} 2-\mathrm{HbA} \mathrm{c}(\mathrm{N}=892)$ & $\mathbf{1 9 7 , 1} \pm \mathbf{4 9 , 5}$ & $224,3 \pm 58,8$ & $<0,001$ \\
$\mathrm{G} 0-\mathrm{G} 2$ at home $(\mathrm{N}=615)$ & $234,2 \pm 63,4$ & $<0,001$ \\
\hline
\end{tabular}

* G0<95mg/dL, G2<120mg/dL, HbA1c <6\%. Cho Ray Hospital was 188.5 $\pm 42.3 \mu \mathrm{mol} / \mathrm{L}$.

** Mann-Whitney test

Fructosamine values were highest in the target achievement group by the G0 and G2 at home. However, due to the limited number of G0 and G2 home tests, the fructosamine range analysis results were not representative enough.Therefore, we did not choose refer to fructosamine by this test group. Instead,we chose refer to the target fructosamine range in pregnant women who simultaneously tested G0, G2 and HbA1c to achieve the goal.The recommended fructosamine target value in this study was $188.5 \pm 42.3 \mu \mathrm{mol} / \mathrm{L}$.

The study had some limitations such as the data collection was only for women who are diagnosed with GDM and who are examined and treated at Cho Ray hospital. Tests were not alway fully implemented, so it was not exclude the possibility of missing out on subjects with good blood glucose control but without adequate testing, so they did not contribute to the fructosamine reference value.

\section{Conclussion:}

The target fructosamine reference value at

\section{REFERENCES}

1. ADA (2007). Summary and Recommendations of the Fifth International Workshop - Conference on Gestatinal Diabetes Mellitus. Fifth International Workshop. Diabetes Care.

2. ADA (2011). "National Diabetes Fact Sheet".

3. ADA (Ed.) (2012). Standards of medical care in diabetes.

4. Le Huy Truong, Chi V. Le, "The role of serum Fructosamine as a monitoring tool in gestational diabetes mellitus treatment in Vietnam". Presented at the ADS and ADEA 2015 Annual Scientific Meeting, Adelaide Convention Center, South Australia.

5. Parkland Health \& Hospital System's Homeless Outreach Medical Services (2003 ). "Healthy Living with Diabetes Program".

6. Sacks David A. (Ed.) (2012). Diabetes \& Pregnancy: A Guide to a Healthy Pregnancy. 